\title{
Registered Nurses' Perceptions of Factors Contributing to Trust-Based Public Management
}

\author{
Bibi Estev, Ami Hommel \\ Faculty of Health and Society, Department of Care Sciences, Malmö University, Malmö, Sweden \\ Email: bibi.estev@gmail.com, ami.hommel@mau.se
}

How to cite this paper: Estev, B. and Hommel, A. (2020) Registered Nurses' Perceptions of Factors Contributing to TrustBased Public Management. Open Journal of Nursing, 10, 1126-1141.

https://doi.org/10.4236/ojn.2020.1011080

Received: October 17, 2020

Accepted: November 27, 2020

Published: November 30, 2020

Copyright $\odot 2020$ by author(s) and Scientific Research Publishing Inc. This work is licensed under the Creative Commons Attribution International License (CC BY 4.0).

http://creativecommons.org/licenses/by/4.0/

\section{(c) (i) Open Access}

\begin{abstract}
Aim: The aim of this study was to illuminate registered nurses' (RNs) perceptions of Trust-Based Public Management (TBPM) in Swedish health care. Design: This study follows a phenomenografic approach guided by Ference Marton's philosophy. Methods: Semi-structured interviews were used to identify variations in RNs' perceptions of TBPM. Between February and April 2019, 24 RNs from five Swedish public healthcare departments participated in the study. Results: The results show that none of the participants had previously heard about the work of the Swedish Delegation for TBPM. The study revealed perceptions those politicians and managers were absent from the workplace, that power had been displaced to HR, and that perceptions of trust in the leadership and of working to guidelines varied. Perceptions varied between RNs employed by the municipalities and by the hospitals concerning administration, the time allotted for work, cooperation, and education.
\end{abstract}

\section{Keywords}

Leadership, New Public Management, Organization, Registered nurses,

Trust Based Public Management

\section{Introduction}

With New Public Management (NPM) came the idea that public organizations should be led by professional managers, referred to as new managerialism. This study explores how new managerialism affect professional autonomy and the trust based public management (TBPM) in a public organization. Based on the findings from this study, Registered Nurses (RN) highlights the importance of shared governance if the quality of care is to be delivered. 
The term NPM came from the private sector to the public sector in the early 1990s. NPM works as a role model for the public sector in terms of governance, leadership, and economic restraint where work discipline is prioritized. NPM was coined by scholars from UK and Australia who were working in the areas of public administration [1]. At the end of 1980s, the Swedish healthcare service suffered major financial problems leading to a willingness to change the traditional organization of governance. For this reason, NPM which has had a major impact internationally was introduced to emulate companies operating in a competitive market [2]. The consequences of using NPM in the public sector internationally have led to a widespread sense of micromanagement in public activities, where the employees feel they cannot use their skills, competence, and experience in the best way. Staff feels that the models used in the public sector focus more on statistical variables than on care quality [3]. The professionals perceive the burden of administration as particularly unnecessary because it produces no value for the patients. This type of administrative work is described as creating illegitimate work tasks [4] [5]. The Delegation for TBPM was introduced in Sweden in 2016 by the government to facilitate the move from a quantitative to a more qualitative control system to benefit both citizens and companies. The mission was to analyze the existing situation and present proposals about how the management of welfare services in the public sector could be developed within existing regulatory frameworks to make more use of the competence and experience of employees [6]. TBPM is described as successful in creating benefits and quality for residents who need support and care. TBPM is a system whereby governance, culture and working methods focus on the purpose of the business and the users' needs, and where each decision level actively works to stimulate cooperation and an overall perspective in order to build trustworthy relationships and ensure that the employee can, wants and dares to help the users. TBPM has three cornerstones, designated as culture, organization, and steering, which interact with each other. There are also seven principles: trust, focus on the user, support from the administration, openness, delegation, cooperation, and holistic thinking. TBPM in the public sector can be defined as a collection of principles aimed at reducing unnecessary control and taking better advantage of the skills of employees to create better quality services for the users [6]. Trust is the most important principle or success in TBPM. Ham's [7] definition of trust is willingness to engage oneself in a relationship where there is a reliance on either a person(s) or thing(s), with an expectation that vulnerability may arise from both parties. When employees feel committed and involved in the work and organization, they contribute to improved results and feel more satisfied with handling difficult moments in a better way [8] [9] [10] [11].

\section{Background}

Much has appeared in the literature about trust between RNs and patients [12]. 
The public's trust in nursing shows that RNs are the most highly trusted professionals in terms of honesty and ethical integrity [13]. Trust among staff within the social structure of healthcare and nursing environments is a more complex phenomenon, less widely explored within literature [14]. Galvin \& Timmins [15] state that when the nurse manager supported and showed confidence in the RNs, regarding personal issues and competence, it led to staff motivation, and enhanced morale and confidence. Earlier studies focus on RNs' trust of the nurse management and do not include the other elements that are part of TBPM. Research is also lacking on RNs' perceptions of TBPM considering the framework that the Swedish Delegation for TBPM has produced. This study, therefore, aims to illuminate RNs' perceptions of TBPM in their work and reveal any eventual effects of the Swedish Delegation's framework in the RNs' workplace. This aim was addressed through the following research question: What are your perceptions of TBPM in your workplace?

\section{Method}

\subsection{Setting}

Four departments in four hospitals and four health care departments in four municipalities were invited to participate in the study. The criteria for the invitation were based on the scope of the study, the department was chosen by size of population and geographical location in southern Sweden. Two departments in two hospitals and three health care departments in three municipalities agreed to participate. The study was conducted in the Departments of Operation Theatre and of Medicine in two hospitals and in the Department of Healthcare in three municipalities and took place between February and May $2019(\mathrm{~N}=24)$.

\subsection{Design}

The study was performed in accordance with the phenomenographical approach by Ference Marton [16] to illuminate registered nurses' (RNs) perceptions of Trust-Based Public Management (TBPM) in Swedish health care. Phenomenography is a field of descriptive research concerned with the different ways of experiencing and understanding various phenomena that people have of various phenomena in the world around them. Phenomenography make the distinction between the first and second order perspective. The first perspective is built on collected fact. The second perspective is not interested in what is true or false, but instead want to describe how other people experience different aspects of reality. Therefor the main purpose of phenomenography is to focus on the perspective of the second order [16] [17].

The method for data collection was individual face-to-face interviews [18]. The questions asked (semi-structured) were general rather than specific, to give all participants an opportunity to voice their opinions on the same issues. All 24 participants were asked about the research question: What are your perceptions of TBPM in your workplace? The follow-up questions were: What do you mean? 
Can you clarify that? Can you give an example? Can you develop your thoughts? All interviews were transcribed verbatim; The criteria for the strategic selection of participants were that they had worked for more than three months in their current department in a hospital or municipality, and that they varied regarding to background, age, and gender. Data were analysed by the seven steps inspired by Sjöström \& Dahlgren [19] which including familiarization, compilation, condensation, grouping, comparison, naming and contrastive comparison. Familiarization is the first step in analyzing the data in getting familiar with the material. After transcribing the interviews reads through several times to familiarize themselves with the material and get a clear idea of the content. Compilation: As a second step, the author should find extract relevant and meaningful notions/ideas/concepts. Condensation: In the third step, the sentences condensed to extract the essential parts. Grouping: In the fourth step, a preliminary grouping of the findings should be created to find a correlation between them. The condensed sentences inserted into the different preliminary categories based on their content. Comparison: In the fifth step, the essential parts in each of the preliminary categories' analyses. The analysis aimed is to find similarities and differences between categories in different groupings. Naming: In the sixth step, the categories are named based on actual content. These categories are called descriptive categories. Contrastive comparison: In the seventh and last step, the similarities, differences, and unique characteristics between the categories are described. Each descriptive category contains similarities and differences within the same descriptive category and defined as the sample space or possibility space.

\subsection{Sample}

Female and male in the ages between 25 and 64 years with a variety of experience participated in the study. The RNs had worked in their current positions for between six months and 23 years. Table 1 contains information on the participants.

\subsection{Analysis}

The first step in the analysis was to read the text from the transcribed interviews several times to gain familiarity with the material and a clear idea of the content. In the second step, all statements related to the purpose of the study were identified. Parts of the text that were deemed to be of no importance for the study's objective were discarded. In the third step, the sentences retained were condensed to extract their most essential parts. In the fourth step, preliminary categories (groups) were created into which the condensed sentences were placed, based on their content, in to reveal any correlations between them. The sentences were examined many times and the categories were revised twice. In the fifth step, the essential parts in each of the preliminary categories were analysed, to find similarities and differences between categories in different groupings. 
Table 1. Characteristic of the participants.

\begin{tabular}{cc}
\hline Characteristics & $\begin{array}{c}N=24 \\
(\%)\end{array}$ \\
& $(\mathrm{MV})=$ Mean Value \\
\hline Female & $20(83)$ \\
\hline Male & $4(17)$ \\
\hline Age groups years & $\mathrm{N},(\%),(\mathrm{MV})$ \\
$25-42$ & $11,(46),(33)$ \\
$43-54$ & $4,(38),(50)$ \\
$55-64$ & $9,(16),(59)$ \\
\hline $1-11$ & $\mathrm{~N},(\%),(\mathrm{MV})$ \\
$12-24$ & $12,(50),(5)$ \\
$25-34$ & $7,(29),(17)$ \\
\hline Number of years as RN & $5,(21),(29)$ \\
\hline 6 months - 8 year -23 & $\mathrm{~N}(\%),(\mathrm{MV})$ \\
\hline Number of years in the current workplace & $20,(84),(3)$ \\
$2,(8),(13)$ \\
$2,(8),(20)$
\end{tabular}

The answers were reviewed several times to ensure that the categories were relevant to the purpose of the study. In the sixth step, the categories were given names according to their essential content, based on the various experiences collected throughout the study. In the seventh and final step, (based on the analysis,) similarities, differences and the unique characteristics among the categories were created. This is defined as the sample space or possibility space and constitutes the result of the study. Based on TBPM, the categories and the perceptions were sorted, according to relevance, under each of the three cornerstones (culture, steering, organization).

\subsection{Ethics}

Adhering to the guidelines of the Helsinki Declaration [20], and the World Medical Association [21], the informants received both verbal and written information about the study. Before the interviews started the information about the study and TBPM was repeated, the author stated once again that the participants could withdraw at any time without giving a reason and that all the data were coded in order to preserve anonymity. The material has been treated confidentially; only the researcher has had access to it. The author contacted the nurse manager in each department to inform them and provide written information about the study, which they then passed on to the $\mathrm{RN}$ in each department by e-mail. The RNs who agreed to participate in the study were asked to 
contact the author by e-mail. Data were obtained by means of audio-taped individual interviews conducted at a location of the participant's choice and lasting for 20 - 50 minutes. At every interview, the participants were once again given written information about the study and its objective. The participants were also given the opportunity to ask questions before the start of the interview. Ethical approval was not required in this type av study according to Swedish guidelines.

\section{Results}

Below, the variations in RNs' perceptions are presented, in categories under the three cornerstones in TBPM (culture, steering and organization).

\subsection{Culture (Categories 1 - 3: Leadership, Accessibility, Decision) Category 1: Leadership}

The amount of trust in leadership varied depending on how the manager acted in various situations and was perceived differently for different activities. In two of the five workplaces did participants feel they could mainly trust the managers at all levels (Table 2).

"Just outside this area, we have something that we call the luxury corridor. The luxury corridor is the place where management has its offices. Employers, accountants, HR. We are not allowed to pass through their corridor when we are going to dialysis with a patient - we have to walk around the area to another elevator. That gives me the "them and us"-feeling. Because honestly, if we did not have any patients, they would not be sitting in that corridor. It is really simple for me, I am not here for their sake, I am here for the patients." [RN 1]

"The employer is not interested in what we need, to be able to trust them" [RN 7]

"We have had a lot of improvements because our employer listens to us, that I have to say. Our employer works hard." [RN 18]

Table 2. Summary of RNs' perceptions of trusting leadership and lack of trusting leadership and their effects.

\begin{tabular}{|c|c|c|c|}
\hline Trustworthy leadership & $\begin{array}{c}\text { Effects of a trustworthy } \\
\text { leadership }\end{array}$ & $\begin{array}{c}\text { Lack of trustworthy } \\
\text { leadership }\end{array}$ & $\begin{array}{l}\text { Effects of the lack of } \\
\text { trustworthy leadership }\end{array}$ \\
\hline $\begin{array}{l}\text { The manager: } \\
\text { - Relays suggestions } \\
\text { - Gives feedback } \\
\text { - Listens to RN } \\
\text { - Has an open climate to share } \\
\text { opinions }\end{array}$ & $\begin{array}{l}\text { The RNs: } \\
\text { - Relate to the value words } \\
\text { - Feel proud } \\
\text { - Share their opinions } \\
\text { - Want to be involved in new } \\
\text { projects } \\
\text { - Feel secure about patient care }\end{array}$ & $\begin{array}{l}\text { - Control from the top } \\
\text { - No possibility to influence } \\
\text { anything } \\
\text { - The manager does not convey } \\
\text { improvement suggestions } \\
\text { upwards in the organizations } \\
\text { - Lack of feedback from the } \\
\text { manager }\end{array}$ & $\begin{array}{l}\text { The RNs: } \\
\text { - Feel less involvement } \\
\text { - Experience stress } \\
\text { - Feel that time has been taken } \\
\text { from patient care and wasted } \\
\text { - Avoid participating in the next } \\
\text { project } \\
\text { - Cannot identify with the vision } \\
\text { of the organization } \\
\text { - Experience a feeling of "us } \\
\text { and them" between staff and } \\
\text { managers }\end{array}$ \\
\hline
\end{tabular}




\section{Category 2: Accessibility}

There was a recurring experience among the participants that the employers and politicians were not present in the workplaces (Table 3 ).

"It would be great if politicians were interested in our work and joined us at work for a day" [RN 6]

"Sometimes we get information by email from the employers. We haven't so much contact with them. They don't use to be here so often" [RN 24]

\section{Category 3: Decision}

The absence of managers and politicians was closely linked to the participants' experiences that decisions did not benefit the patients or were economically indefensible (Table 3).

"Now and then there are decisions from higher management that we are told to just adapt to". If we had been able to participate more, they would also understand that these decisions are not always in the patients' best interest." [RN 2]

"I think our politicians make a lot of weird decisions, and I believe that if we had a say in the matter, health care would have worked differently than it does today". [RN 9]

\subsection{Steering}

Categories: Administration, Information/Meeting, Routines, Time.

\section{Category 4: Administration}

\section{Administration support}

In all the workplaces, there was a lack of trust in the human resources department (HR) (Table 4).

"Us nurses were on a forum in the region for the future of nurses. A person from the central department of HR gave lectures and called us "the foot people". The trust in the region was a hefty blow. Then you start to wonder? Is this an approach that is anchored in the leading top?" [RN 3]

"HR have become our new manager, our managers have no mandate anymore" [RN 8]

"There are directives for salary auditing, and so there is a budget and HR, and then there was something else" [RN 10]

Table 3. Summary of RNs' perceptions of the leadership's accessibility and decisions.

\section{Accessibility}

- Lack off accessibility from the top leadership

- Want politicians and top managers to be more present

- Want to cooperate.
3. Decision

- Hard to understand the meaning of decisions

- Decisions that neither benefit the patient nor are economically defensible

- Want to get involved in decisions and contribute knowledge

- A feeling of lack of in the professional's knowledge from the topleadership 
Table 4. Summary of RNs' perceptions of administration support (HR), information/meeting, routines and responsibility.

\begin{tabular}{|c|c|c|c|}
\hline 4. Administration support (HR) & 5. Information/meeting & 6. Routines & 10. Responsibility \\
\hline $\begin{array}{l}\text { - Lack of trust in the people } \\
\text { working in the HR department } \\
\text { - Don't know who HR are or } \\
\text { their role } \\
\text { - HR have more power than the } \\
\text { mangers have }\end{array}$ & $\begin{array}{l}\text { - Good information from } \\
\text { employers } \\
\text { - RNs want dialog instead of } \\
\text { monologue } \\
\text { - Different kind of meetings } \\
\text { - Talk about basic values in the } \\
\text { team } \\
\text { - Doesn't prioritize talking about } \\
\text { trust } \\
\text { - Important to talk about trust }\end{array}$ & $\begin{array}{l}\text { Guidelines: } \\
\text { - Which are up to date } \\
\text { - Which are not up to date } \\
\text { - Which are followed by } \\
\text { colleagues } \\
\text { - Have not been followed by } \\
\text { colleagues } \\
\text { - Feel a lack of trust when } \\
\text { colleagues don't follow the } \\
\text { guidelines }\end{array}$ & $\begin{array}{l}\text { RNs: } \\
\text { - Want to be included in } \\
\text { decisions-making processes } \\
\text { - Want a solution from the } \\
\text { manager } \\
\text { - Don't want to take decisions } \\
\text { by themselves } \\
\text { - Who don't take responsibly for } \\
\text { - Necisions? } \\
\text { - Need to get more involved in } \\
\text { - Go to meetings when employers } \\
\text { invite }\end{array}$ \\
\hline
\end{tabular}

\section{Documentation}

$\mathrm{RN}$ in the municipal organizations considered documentation necessary and did not see it as a burden imposed by the participants working in the hospital's medical department (Table 5).

"The administration is necessary and shows what we do" [RN 14]

"We spend a lot of time on administrative work. Different drug lists, Journal systems and laboratory values that are difficult to find. We find it diffi-

cult to get an overall picture of the patient, which creates a lack of trust" [RN 5]

\section{Category 5: Information/meeting}

The quality of information varied within the workplaces, which affected trustworthiness. The structure of the meetings depended on what organization they were employed in. None of the participants had heard about Trust-Based Public Management before the interviews (Table 4).

"News that are good to know are published on the intranet. Our managers are good at informing us, both on what comes from them but also higher up" [RN 4]

"It is difficult to have conversations when the manager is holding back information as a secret. It's ok to say the wrong thing and come back and say it was wrong" [RN 11]

"I am missing continuous communication at all levels." [RN 15]

"There is good information on the intranet, but it is usually predominantly positive things which isn't good because we, the employees, know that there are huge problems that need to be lifted. We can use chat to discuss problems, to meet politicians. I ve never met them" [RN 19]

\section{Category 6: Routines}

It was important for RNs to have guidelines. Some guidelines were updated and easily accessed, and some were out of date. Some employees followed the guidelines, and some didn't (Table 4). 
Table 5. Summary of the nurses' different perceptions of documentation, time for work, cooperation and education between municipalities and hospitals.

\begin{tabular}{|c|c|c|}
\hline Category & $\mathrm{RN}$ in the municipalities & $\mathrm{RN}$ in the hospitals \\
\hline 4. Documentation & $\begin{array}{l}\text { - Think documentation is important } \\
\text { - Do not perceive documentation as } \\
\text { a burden } \\
\text { - Think documentation confirms } \\
\text { what they do } \\
\text { - Documentation provides feedback } \\
\text { on results } \\
\text { - Documentation helps develop care }\end{array}$ & $\begin{array}{l}\text { - Documentation reduces time spent } \\
\text { with patients } \\
\text { - Too many different technological } \\
\text { systems to use } \\
\text { - Time taken for documentation } \\
\text { affects patient safety }\end{array}$ \\
\hline 7. Time for work & $\begin{array}{l}\text { - Have enough time for the work } \\
\text { - Enough of RN }\end{array}$ & $\begin{array}{l}\text { - Stressful } \\
\text { - Shortage of RNs } \\
\text { - No time for breaks } \\
\text { - Each RN have too many patients to } \\
\text { take care of } \\
\text { - Not enough time to update PMs } \\
\text { - Pressure to produce. }\end{array}$ \\
\hline 8. Cooperation & $\begin{array}{l}\text { - Good cooperation with colleagues } \\
\text { - Call for better cooperation with } \\
\text { doctors and nursing assistants } \\
\text { - Do not know if the patient gets } \\
\text { the right care } \\
\text { - Many of the nursing assistants lack } \\
\text { competence and commitment } \\
\text { - No continuity of doctors (employed } \\
\text { in primary care) }\end{array}$ & $\begin{array}{l}\text { - Good teamwork with different } \\
\text { kinds of professionals } \\
\text { - A lot of competence (professional) }\end{array}$ \\
\hline 9. Education & $\begin{array}{l}\text { - Need and want more education } \\
\text { - Request for local training to be } \\
\text { adapted to RNs' competence and } \\
\text { experience. }\end{array}$ & $\begin{array}{l}\text { Satisfied with the continuity of } \\
\text { education and the different forms } \\
\text { of training }\end{array}$ \\
\hline
\end{tabular}

"The staff can't do as they should when the standard treatment plan is not up to date" [RN 17]

"We have updated guidelines but not all employees follow them" [RN 8]

\section{Category 7: Time for work}

There was a clear difference in the experience of stress between hospitals employees and those in municipal workplaces. The RNs at the hospitals do not have enough time to care for their patients, take breaks or update PMs. The work in the operating theatres described as a stressful working environment with many patients and a "pressure to produce", which RN in the municipalities did not perceived (Table 5).

"Nurses ends the job all the time because it's too heavy, it's too stressful, we don't have time, so we don't have time" [RN 12]

"It's a lot about production and we're in a hurry. As a surgical nurse, you sometimes feel that the program is delayed. They often ask if $\mathrm{Im}$ not finished with the tables soon. But the set-up is included in the production 
and it must be done correctly otherwise you can risk that the patient gets a post-operative wound infection, or if not, or that the right instrument is not at hand, which can cause complications or delays in the operation" [RN 16]

\subsection{Organization}

Categories: Cooperation, Education, Responsibility Category 8: Cooperation

The experiences of trust and lack of trust in relation to colleagues emerged as a key topic. There was a difference in the trust experienced between municipal and hospital employees. The teamwork on the wards in both hospitals functioned well but in the municipal workplaces there were uncertainties about whether the tasks were completed and whether the patient had received the proper care. The participants working in the hospitals had more trust in other professionals than those working in municipal organizations (Table 5).

"Between my colleagues it's wonderful. I have hundred percent trust to them. We are helping each other's with all the duties" [RN 13]

"It would have been so fun and much easier to do a good job if everyone who chose this profession was here to do their best. To put an honour in the job, gather knowledge and seize his knowledge. I do not think the $R N$ feel it that way, but among nursing assistants there is a lack of professional pride. I don't know why? because it's a hugely important job" [RN 20]

"I have a colleague who is a nursing assistant that I feel I can trust. She always doing the "little extra for the patient" [RN 4]

"At meetings we agree with the nursing group not to criticize a colleague's assessments before the nursing staff. When we talk about it, there are many who have been involved in doing so. Some colleagues say they can take it because they have been nurses for so long. They think that it is more the younger nurses who care. I rather think it depends on how you are as a person than how long you have been a nurse" [RN 23]

\section{Category 9: Education}

It was important for the confidence of the participants that the employer invested in education. The participants who worked in the hospitals were satisfied with the range of training offered (lectures, team training and Case seminars). Those working in the municipality wanted more education and local training adapted to the RNs' level of knowledge and experience (Table 5).

"We have had special case seminars at special events and where the doctors have been involved. I can see it as part of trust where you are not looking for errors but instead, want to highlight what we did well and above all what we can improve so that it does not happen again" [RN 2]

"I am thinking of the internal training that our managers say we must go to that affect the experience of trust. These trainings are more adapted to new $R N$ and not to $R N$ who have been in the municipality for 20 years. Then I 
think that the managers do not have control. You get frustrated at being forced to take a course that gives nothing. Don't the managers think we have more skills than that?" [RN 22]

"We need more education because it was a long time ago that I finished my nursing degree" [RN 11]

\section{Category 10: Responsibility}

There were various opinions about the amount of responsibility that the participants were prepared to take in order to meet the dilemmas and challenges within the organization (Table 4).

"I feel like we are trusted more when we get to participate in the decision-making process but not everyone does as we have decided" [RN 14] "My view is that the employers listening to us because $P \mathrm{~m}$ used to go to meetings and see that they have a good will. Many of my colleagues don't go to the meetings and see what the employers do" [RN 21]

\section{Discussion}

The aim of this study was to illuminate RNs' perceptions of TBPM in their work and reveal any eventual effects of the Swedish Delegation's framework in the RNs' workplace. The study confirms results of previous studies when employees feel involved in the work and organization, they contribute to improved results and feel more satisfied about handling difficult moments in a better way [8] [9] [10] [11]. The study has provided an additional in-depth knowledge of RN's perceptions of the seven principles included in TBPM (trust, focus on the user, support from the administration, openness, delegation, cooperation, and holistic thinking). Overall, the results show that none of the participants had heard about TBPM and the work of the Swedish Delegation for TBPM and indicate that the Swedish Delegation's framework has not reached the healthcare professionals who meet the patients.

The absence of politicians and managers and displacement of power to HR generated different perceptions of trust in the leadership and in whether guidelines existed and were followed. There were variations in perceptions between the activities of the municipalities and the hospitals with reference to administration, time for work, cooperation, and education. The use of NPM as a form of governance has been criticized for increasing unnecessary administration that can be stressful for the professionals and takes time from the patients [4] [22] [23]. In both areas of hospital work, the job was perceived as time-consuming and stressful. In the operating theatre the stress was linked more to high productivity requirements than to administrative burdens. The administrative burden was felt particularly by RNs in medical departments, where the use of different computer systems was perceived as time-consuming, taking time away from patients, and stressful. In the municipal settings there was sufficient time available to complete the tasks and the RNs saw the documentation as a good tool for fol- 
lowing up results. The conclusion here is not to blame the administration for everything but to clarify which aspects of it are burdens. The reason RNs in hospitals experienced stress was because of under-staffing while that was not an issue in the municipalities, owing partly to the higher salaries paid. The RNs in municipal employment were not less stressed because there was cooperation between different professions or more time spent on quality education. This study shows, to the contrary, that the participants working for municipalities wanted more cooperation with other professionals and more education adapted to the RNs training level. Since the lack of RNs is a challenge in the Swedish healthcare system, it could be worth considering the factors which attract RNs to workplaces; perceptions of leadership might be one. The differences between the RNs' perceptions of the leadership depended on how responsive the managers were and how they kept the staff informed about the chances of implementing the changes. It was important for RNs that the policymakers understood the activities and the challenges involved. This suggests that RNs have both knowledge and willingness to contribute to important decisions. The willingness of the participants to be involved, their expectations that management will support them and give them the opportunity to participate in decisions can be aligned with the theory of transformative leadership. According to Yukl [24] transformative leadership is a motivational model with an emphasis on the employee's emotional reactions in relation to the leader. When employees perceive the relationship as meaningful, they experience an increased degree of commitments, patient safety and job satisfaction [25]-[31].

The results of the present study indicate that participants' perceptions result from heavy responsibility and the expectation that a quality service will be delivered. The respondents' questioning in cases where incorrect decisions have been made indicates a high level of responsibility. It would, therefore, seem a good idea to use the competence of RNs and other healthcare professionals in decision-making processes to reduce the risk of making decisions that benefit neither the patients nor the economy. The perception of the shift in power from the formal management to HR caused the participants a lot of concern. There is a lack of research into HR and it would be interesting and useful to have some investigative research into power. The perceptions emerged particularly with reference to the managers' fear of making their own decisions before they had consulted HR. The supportive function that $H R$ is supposed to have vis-à-vis the manager becomes subverted. Evidence from neuroscience shows that fear limits productivity and that individuals and organizations are more successful when people are encouraged to take risks, explore new ideas, and channel their energies in ways that work for them [32]. The RNs were concerned about patient safety when the guidelines were not up to date or not followed by colleagues. Neal \& Griffin [33] state that the organizational climate comprises the common view of the policy, procedures and best practice that the working group has in relation to the security of the organization and can connected with the impor- 
tance of having updated guidelines for providing proper care.

The result shows that relationship between trust and control is a central theme and connecting with Galvin \& Timmins [15] state of the importance to give support and showed confidence in the RNs, regarding personal issues and competence. Shared governance is. a significant impact on the empowerment of clinical nurses. The most emotionally connected managers let their nurses know that they need their help to build the best organizations, possible to improve new methods for best practice and job satisfaction.

\section{Limitation}

Since TBPM do not have implemented in the activities that the participants worked in, there have been limitations in finding out what results for patients TBPM may have given. There have also been limitations in obtaining previous research as TBPM is relatively new as a concept.

\section{Conclusions}

The participants can see a variety of benefits with TBPM and think it is necessary to allow competence and experience to contribute to the decision-making processes if quality care is to be delivered in the future. Based on the results of this study, the following actions are proposed in connection with practical implementing of TBPM:

- That politicians and management show a willingness to get involved in health care to understand the work that the staff does.

- All levels of the organization are made aware of what constitutes trust-based governance and management.

- Structures are created that enable TBPM (common values, objectives, policy, measurement, follow-up).

- Meeting arenas are created where management and staff can build the feeling of togetherness.

- Training in trust-based management is introduced into the nursing program and the education of all professionals who meet patients.

- Patients and staff are being involved at all stages from the beginning in the process of TBPM.

\section{Acknowledgments}

We thank the Registered Nurses' who generously shared their perceptions with us. We also thank the managers in the various organizations who gave permission for the study. You have all made it possible for the study to be carried out.

\section{Authors' Contribution}

Authors $\mathrm{BE}$ and $\mathrm{AH}$ contributed equal to the conceptions and design of the study. BE was responsible for recruitment, data collection, the first data analyse and drafting of the original manuscript. 
$\mathrm{BE}$ and $\mathrm{AH}$ cooperated during the analysis part. $\mathrm{AH}$ reviewed and edited the manuscript. Both authors critically revised the manuscript and have read and approved the final version of the manuscript.

\section{Conflicts of Interests}

The authors declare no conflicts of interest with respect to the authorship and/or publication of this article.

\section{References}

[1] Hood, C. (1991) A Public Management for All Seasons? Public Administration, 69, 3-19. https://doi.org/10.1111/j.1467-9299.1991.tb00779.x

[2] Christensen, T. and Lægreid, P. (2001) New Public Management: The Transformation of Ideas and Practice. Ashgate, Aldershot.

[3] Pollitt, C. and Bouckaert, G. (2011) Public Management Reform: A Comparative Analysis: New Public Management, Governance, and the Neo-Weberian State. Oxford University Press, Oxford.

[4] Anskär, E. (2019) Time Flies in Primary Care: A Study on Time Utilisation and Perceived Psychosocial Work Environment. Linköping University Electronic Press, Linköping. https://doi.org/10.3384/lic.diva-156119

[5] Semmer, N.K., Tschan, F., Meier, L.L., Facchin, S. and Jacobshagen, N. (2010) Illegitimate Tasks and Counterproductive Work Behavior. Applied Psychology, 59, 70-96. https://doi.org/10.1111/j.1464-0597.2009.00416.x

[6] Delegation for Trust-Based Public Management (2018).

https://www.regeringen.se/rattsliga-dokument/statens-offentliga-utredningar/2019/ 10/sou-201943/

[7] Hams, S.P. (1997) Concept Analysis of Trust: A Coronary Care Perspective. Intensive and Critical Care Nursing, 13, 351-356.

https://doi.org/10.1016/S0964-3397(97)81118-4

[8] Altuntas, S. and Baykal, U. (2010) Relationship between Nurses' Organizational Trust Levels and Their Organizational Citizenship Behaviors. Journal of Nursing Scholarship, 42, 186-194. https://doi.org/10.1111/j.1547-5069.2010.01347.x

[9] McEvily, B., Perrone, V. and Zaheer, A. (2003) Trust as an Organizing Principle. Organization Science, 14, 91-103. https://doi.org/10.1287/orsc.14.1.91.12814

[10] Ramo, H. (2004) Moments of Trust: Temporal and Spatial Factors of Trust in Organisations. Journal of Managerial Psychology, 19, 760-775. https://doi.org/10.1108/02683940410568248

[11] Song, J.H., Kim, H.M. and Kolb, J.A. (2009) The Effect of Learning Organization Culture on the Relationship between Interpersonal Trust and Organizational Commitment. Human Resource Development Quarterly, 20, 147-167. https://doi.org/10.1002/hrdq.20013

[12] Donnelly, F. and Wiechula, R. (2006) The Lived Experience of a Tracheostomy Tube Change: A Phenomenological Study. Journal of Clinical Nursing, 15, 1115-1122. https://doi.org/10.1111/j.1365-2702.2006.01384.x

[13] Brenan, M. (2018) Nurses Again Outpace Other Professions for Honesty, Ethics. https://news.gallup.com/poll/245597/nurses-again-outpace-professions-honesty-eth ics.aspx

[14] Mullarkey, M., Duffy, A. and Timmins, F. (2011) Trust between Nursing Manage- 
ment and Staff in Critical Care: A Literature Review. Nursing in Critical Care, 16, 85-91. https://doi.org/10.1111/j.1478-5153.2010.00404.x

[15] Galvin, G. and Timmins, F. (2010) A Phenomenological Exploration of Intellectual Disability: Nurse's Experiences of Managerial Support. Journal of Nursing Management, 18, 726-735. https://doi.org/10.1111/j.1365-2834.2010.01101.x

[16] Marton, F. (1981) Phenomenography-Describing Conceptions of the World around Us. Instructional Science, 10, 177-200. https://doi.org/10.1007/BF00132516

[17] Marton, F. and Booth, S.A. (2013) Learning and Awareness. Taylor and Francis, Mahwah. https://doi.org/10.4324/9780203053690

[18] Polit, D.F. and Beck, C.T. (2017) Essentials of Nursing Research: Appraising Evidence for Nursing Practice. 9th Edition, Wolters Kluwer Health, Philadelphia.

[19] Sjöström, B. and Dahlgren, L.O. (2002) Applying Phenomenography in Nursing Research. Journal of Advanced Nursing, 40, 339-345. https://doi.org/10.1046/j.1365-2648.2002.02375.x

[20] Helsinki Declaration (1964). http://www.cirp.org/library/ethics/helsinki

[21] World Medical Association (2008). https://www.wma.net/policies-post/wma-declaration-of-helsinki-ethical-principlesfor-medical-research-involving-human-subjects

[22] Fuchtbauer, L.M., Norgaard, B. and Mogensen, C.B. (2013) Emergency Department Physicians Spend Only 25\% of Their Working Time on Direct Patient Care. Danish Medical Journal, 60, A4558.

[23] Törnqvist, J., Törnvall, E. and Jansson, I. (2016) Double Documentation in Electronic Health Records. Nordic Journal of Nursing Research, 36, 88-94. https://doi.org/10.1177/2057158515625368

[24] Yukl, G.A. (2006) Leadership in Organizations. 6th Edition, Prentice Hall, Upper Saddle River. Pearson Education, New Jersey

[25] Bass, B.M., Avolio, B.J., Jung, D.I. and Berson, Y. (2003) Predicting Unit Performance by Assessing Transformational and Transactional Leadership. Journal of Applied Psychology, 88, 207-218. https://doi.org/10.1037/0021-9010.88.2.207

[26] Boamah, S.A., Laschinger, H.K.S., Wong, C. and Clarke, S. (2018) Effect of Transformational Leadership on Job Satisfaction and Patient Safety Outcomes. Journal of Nursing Outlook, 66, 180-189. https://doi.org/10.1016/j.outlook.2017.10.004

[27] Merrill, K.C. (2015) Leadership Style and Patient Safety: Implications for Nurse Managers. Journal of Nursing Administration, 45, 319-324. https://doi.org/10.1097/NNA.0000000000000207

[28] Mullen, J., Kelloway, E.K. and Teed, M. (2011) Inconsistent Style of Leadership as a Predictor of Safety Behaviour. Work \& Stress, 25, 41-54. https://doi.org/10.1080/02678373.2011.569200

[29] Möllering, G., Bachmann, R. and Hee Lee, S. (2004) Exploring Associations between Employee Empowerment and Interpersonal Trust in Managers. Journal of Managerial Psychology, 19, 556-570. https://doi.org/10.1108/02683940410551480

[30] Ree, E. and Wiig, S. (2019b) Linking Transformational Leadership, Patient Safety Culture and Work Engagement in Home Care Services. Nursing Open, 7, 256-264. https://doi.org/10.1002/nop2.386

[31] Walumbwa, F.O., Wang, P., Lawler, J.J. and Shi, K. (2004) The Role of Collective Efficacy in the Relations between Transformational Leadership and Work Outcomes. Journal of Occupational and Organizational Psychology, 77, 515-530. 
https://doi.org/10.1348/0963179042596441

[32] Brown, P., Kingsley, J. and Paterson, S. (2015) The Fear-Free Organization: Vital Insights from Neuroscience to Transform Your Business Culture [Elektronisk resurs]. Kogan Page, London.

[33] Neal, A. and Griffin, M.A. (2002) Safety Climate and Safety Behaviour. Australian Journal of Management, 27, 67-75. https://doi.org/10.1177/031289620202701S08 